\title{
Importance of Reassessment for Patient waiting for Knee and Hip Arthroplasty for prioritization of Surgery
}

\author{
Syed Mohsin Ali ${ }^{2 *}$, Mohammed Fouad Alabdulqader ${ }^{1}$ and E Masterson ${ }^{3}$ \\ ${ }^{1}$ Department of Orthopedic Surgery, Johns Hopkins Aramco Health care, Saudi Arabia \\ ${ }^{2}$ Department of Trauma and Orthopaedic Surgery, Bahrain Defense Forces Hospital, Bahrain \\ ${ }^{3}$ Department of Trauma and Orthopedic Surgery, Mid-Western Regional Hospital, Republic of Ireland
}

Submission: April 08, 2020; Published: April 16, 2020

*Corresponding author: Syed Mohsin Ali, Consultant Orthopaedic Surgeon, Department of Trauma and Orthopaedic Surgery, Johns Hopkins Aramco Health care, Saudi Arabia

\begin{abstract}
Introduction: There is an increase in demand on total knee and hip replacement surgeries, which can lead to long waiting list. Hip and knee scoring system is an important tool to help determine the need for early prioritization for surgery.

Method: We reviewed 153 patients waiting for hip and knee arthroplasty surgery. HHS (Harris Hip Score) \& AKSS (American Knee Scoring System) were used to prioritize the patient for surgery depending on their deterioration of the score and increase clinical need. These scores were measured both at time of initial listing and reassessment after six months.

Result: 15 patients who were waiting for THR showed deterioration in HHS score up to 10.7. Similarly, 5 patients for TKR showed deterioration in AKSS scores up to (24.42). In total 15 (9.8\%) were prioritize for early surgery out of 153 patients. Postoperative HHS and AKSS were measured in this prioritized group.
\end{abstract}

Conclusion: Patients requiring total hip or knee replacement can deteriorate while on the waiting list. Periodic assessment of patients can help to reprioritize the patient according to their clinical need. HHS and AKSS are well validated and easy to perform in clinical practice.

Keywords: Arthroplasty; HHS (Harris Hip Score); AKSS (American Knee Society Score); Prioritization and deterioration

\section{Introduction}

The most common arthroplasty surgery is for hips and knees. Approximately annually 800,000 primary total hip replacements and 300,000 total knee replacement are performed for hip and knee arthritis [1,2]. The success of hip and knee arthroplasty resulted in increase in demand and waiting list. An average referral to time of surgery can be up to more than one year in some European countries [1,3]. It has been reported that a variety of attempts have been made to develop criteria for prioritization of these patients $[4,5]$. There are some studies have addressed ways in management of the waiting list. However, a few have been written about the importance of assessment and re-assessment for patients who are waiting for surgery [6]. In our department, we develop a system of assessment and reassessment for the patients who are on the waiting list for hip and knee arthroplasty. In this project, we have evaluated the changes in the hip and knee score in a cohort of patients who waited for surgery more than six months.

\section{Patient and Method}

In our regional orthopedic hospital patients are referred by Family doctors to the orthopedic surgeon and after initial assessment these patients go on the waiting list. They are also referred to arthroplasty specialist nurse. This nurse is fully qualified with special interest in orthopedic surgery. For this project, she was trained further by local surgeons regarding measuring HHS, AKSS and how to do proper clinical assessment. These patients were reassessed at six months interval. Harris hip score and American knee society scores with a brief medical history and clinical examination was recorded. If any deterioration from their score and clinical evaluation, these patients were 
prioritized for surgery within the next 6 weeks due to increase in clinical demand.

53 patients who waited more than six-months for surgery were reassessed. Patients age, changes in Harris hip score and American knee society score were recorded. These scoring systems have been validated extensively [6-8]. HHS gives a maximum score of 100 points, based on pain symptoms, functional activity, range of motion and deformity. While AKSS consist of two main parts. First measuring knee score, which consider pain, stability and range of motion as the main parameters. Second part measures the function score utilizing walking distance and stair climbing as main measures. Score ranges from 0 (severe disability) 200 (normal). We also recorded the number of patients who were prioritize for early surgery and compared the initial reassessment scores and post-operative score.

\section{Result}

Total 153 patients for the primary hip and knee arthroplasty were referred to reassessment follow-up clinic. Out of 153 patients, 105 (68.62\%) were for the total hip replacement and 48 $(31.37 \%)$ were for the total knee replacement. Patients for THR $(n=105)$ ranged in age 30-90 years with mean age of 60 years. Average initial HHS was 63.70 (range from 7 to 100). Average hip score on reassessment was 53.00 (range from 44 to 59). Out of 105 patients, for THR 15 patients (14.28\%) showed deterioration in their score up to 10.7 (Table 1). Patients for TKR $(n=48)$ had a mean age of 65.5 years range from 41-90 years. Average initial AKSS of these patients were 99.83 ranges from 70-200. After reassessment in six months mean score was 75.42 (ranged from 61-89) representing deterioration in score up to 24.42 (Table 2). In this group 5 patient $(10.41 \%$ ) were prioritize for early surgery (Table 2) 6 months post operatively these patients were reviewed, and an average HHS was 88.9 as compared to 53 prior to surgery. Similarly, patients after TKR reassessed and their average score post operatively was 148.75 as compared to pre-operative 75.42 (Table 3).

Table 1: Mean scores difference between initial and reassessment after six months.

\begin{tabular}{|l|c|c|c|}
\hline & Initial score & Reassessment score & Difference \\
\hline HHS (THR) & 63.70 & 53 & 10.70 \\
\hline AKSS (TKR) & 99.83 & 75.42 & 24.42 \\
\hline
\end{tabular}

Table 2: Patients prioritize for early surgery and their mean scores.

\begin{tabular}{|l|c|c|}
\hline & $\begin{array}{c}\text { Total number of Patients } \\
\text { required prioritization }\end{array}$ & $\begin{array}{c}\text { \% of patient required } \\
\text { early Surgery }\end{array}$ \\
\hline THR (n105) & 15 & $14.28 \%$ \\
\hline TKR (n48) & 05 & $10.4 \%$ \\
\hline
\end{tabular}

Table 3: Improvement in post-operative scores for patients after prioritization.

\begin{tabular}{|c|c|c|c|c|}
\hline & $\begin{array}{c}\text { Number of } \\
\text { patients }\end{array}$ & $\begin{array}{c}\text { Mean } \\
\text { pre-operative } \\
\text { score }\end{array}$ & $\begin{array}{c}\text { Mean } \\
\text { post-opera- } \\
\text { tive score }\end{array}$ & Difference \\
\hline THR & 15 & 53 & 88.9 & 35.9 \\
\hline TKR & 05 & 75.42 & 148.79 & 73.37 \\
\hline
\end{tabular}

\section{Discussion}

There are many different methods for assessment have been described in literature; however, its implementation is a difficult task [6]. Clinical prioritization can be strengthened by the use of a scoring system. It will assist in determining those patients who are in greater clinical need of surgery. Harris hip score and American knee society score are not difficult to perform and completed in same clinic visit $[6,9]$. Literature review showed that there are various studies believed that patient with increasing pain and disability should be prioritized for early surgery $[5,10$ 12]. Not many studies illustrate the importance of revalidation and assessment of patients while waiting for surgery. Periodic review provides identifying the patients who are deteriorating and requires earlier surgery than their initial score would suggest.

Results of this small retrospective study showed that there was $9.8 \%$ of patients required early prioritization for surgery based on clinical need and deterioration in their score. Post-operative evaluation of scores in these 15 patients shows significant improvement (Table 3).

\section{Conclusion}

In conclusion, this small study emphasizes the importance of regular review and reassessment of waiting list to allow reprioritization according to changing clinical need rather than waiting time. Simple validated scoring system like HHS and AKSS can be used for reassessment. Due to small number of patients' statistics, analysis was not done. We advocate for larger and multicentric study.

\section{References}

1. West R R (1982) Shortening waiting list in orthopedic surgery outpatients clinic. BMJ 284: 728-730.

2. Knutsson S, Engberg IB (1999) An evaluation of patients' quality of life before, 6 weeks and 6 months after total hip replacement. Journal Adv Nurse 30(6): 1349-1359.

3. Kavalieratos T, Nortje M, Dunn RN (2017) Hip and knee arthroplasty waiting list - how accurate and fair? S Afr Med J 107(4): 323-326.

4. C D Naylor, J I Williams (1996) Primary hip and knee replacement surgery; Ontario criteria for case selection and surgical priority. Qual Health Care 5(1): 20-30.

5. GM Woolhead, JL Donovan, JA Chard, PA Dieppe (2002) Who should have priority for a knee joint replacement? Rheumatology 41(4): 390394. 
6. R Kingston, M Carey, E Masterson (2000) Need -based waiting list for hip and knee arthroplasty. Irish journal of medical sciences 169(2): 125-126.

7. Liow RY, Walker K, Wajid MA, Bedi G, Lennox CM (2000) The reliability of American knee society score. Acta Orthop Scand 71(6): 603-608.

8. Mahomed NN, Arndt DC, McGrory BJ, Harris WH (2001) The Harris hip score: comparison of patient's self-report with surgeon assessment. J Arthroplasty 16(5): 574-580.

9. Lovelock TM, Broughton NS, Williams CM (2018) The Popularity of Outcome Measures for Hip and Knee Arthroplasties. J Arthroplasty 33(1): 273-276.
10. Mancuso CA, Ranawat CS, Esdaile JM, Johanson NA, Charlson ME (1996) Indication for total hip and knee arthroplasties-results of orthopaedic survey. J Arthroplasty 11(1): 34-36.

11. Roy CW, Hunter J (1996) What happens to patients awaiting arthritis surgery? Disability and rehabilitation. 18(2): 1010-1105.

12. Wright JG, Coyte P, Hawker G, Bombardier C, Cooke D, et al. (1995) Variation in orthopaedic surgeon's perception of the indications for and outcome of knee replacement. CMAJ 152(5): 687-697.

\section{Your next submission with Juniper Publishers will reach you the below assets}

- Quality Editorial service

- Swift Peer Review

- Reprints availability

- E-prints Service

- Manuscript Podcast for convenient understanding

- Global attainment for your research

- Manuscript accessibility in different formats ( Pdf, E-pub, Full Text, Audio)

- Unceasing customer service

Track the below URL for one-step submission https://juniperpublishers.com/online-submission.php 